\title{
El orden de la representación en la novela colombiana de la primera década del siglo XXI:
}

\author{
la transgresión de La celda sumergida*
}

\author{
The Order of Representation in the Colombian Novel \\ of XXI Century First Decade. The Transgression of La Celda Sumergida
}

Yamilet Angulo Noguera**

\section{Resumen}

El objetivo de este estudio es describir y revisar la dinámica del campo de la novela de la primera década del siglo XXI que da cuenta de un orden de la representación que aboga por la inclusión de formas expresivas divergentes y por una percepción del género en la que se emprenden pactos narrativos que problematizan la relación fición-realidad. El análisis sociocrítico de $L a$ celda sumergida, de Julio Paredes, es el punto de partida de una reflexión alrededor de la lucha por la legitimidad en la que se cuestiona el horizonte fijando lógicas enunciativas centrales. Este estudio parte de los planteamientos de los trabajos teóricos en literatura de Pierre Bourdieu, Georg Lukács, Lucien Goldmann, Mijail Bajtin y de la reflexión modernidad-posmodernidad realizada por Gianni Vattimo, Zygmunt Bauman, Jorge Orlando Melo y Salomón Kalmanovitz.

\section{Palabras clave:}

Orden de la representación, racionalidad logocéntrica, divergencia, transgresión, ficción-realidad, campo de la novela colombiana.

\section{Abstract}

The purpose of this essay is to describe and to review the dynamic of the premier decade of the twenty one century novel champ. This literary movement realizes an order of representation that procures the inclusion of diverse expressive manners and the perception of the genre where new narrative pacts make complex the relationship between fiction and reality. The analysis sociocritical of La celda sumergida by Julio Paredes is the starting point of a reflexion around the fight for legitimacy in which the horizon fixed by central enunciative logics are demanded. To write this essay, the theoretical contributions of Pierre Bourdieu, Georg Lukács, Lucien Goldmann, Mijail Bajtin and the critical thinking around modernity-posmodernity developed by Gianni Vattimo, Zygmunt Bauman, Jorge Orlando Melo and Salomón Kalmanovitz.

Key words:

Order of representation, logocentric rationality, divergence, transgression, fiction-reality, Colombian narrative.

* Obra estudiada. Paredes, Julio. (2002). La celda sumergida. Bogotá: Alfagurara.

** Profesora Facultad de Humanidades de la Universidad Pedagógica Nacional, Departamento de Lenguas e investigadora de la Facultad de Ciencia y Educación del Proyecto Curricular de Lengua Castellana de la Universidad Distrital Francisco José de Caldas. yamileta527@gmail.com 


\begin{abstract}
Así, la novela posmodernista renuncia a una estructura logocéntrica tradicional para, liberándose de ella, girar sobre sí misma y dejar atrás la idea de centro.

Este tipo de ficción invierte el tiempo y el espacio, rechaza convenciones tradicionales y hace referencia al placer de la creación artística y al renacimiento de la imaginación frente al realismo tradicional. Se dirige por tanto al abandono de dicho realismo convencional o más concretamente a la exploración de las relaciones entre ficción y realidad'.
\end{abstract}

La razón moderna, encarnada en la figura del sujeto, era un reclamo por el progreso ininterrumpido de la humanidad en todos los ámbitos del saber y de la cultura. Ostentó el poder durante varios siglos y fundamentó todas las formas de simbolizar la vivencia. Su función consistió en articular de manera coherente y homogénea un lenguaje cuyo uso codificado sancionaba una forma del pensamiento occidental, excluyendo o marginando otras.

A Colombia el orden de la representación moderno ${ }^{2}$ llega con la Conquista española y la evangelización de los indígenas; hecho que implica muchas consideraciones a la hora de particularizar las posturas estéticas que se gestan de este evento histórico. España, al llegar al continente americano con un proceso modernizador incipiente (dada la lucha contrarreformista) cierra sus puertas al mundo científico y a la ideología liberal, aferrándose al

1 José Antonio Gurpegui Palacios; Mar Ramón Torrijos. (2005). "Contexto y perspectiva general del posmodernismo". Alcalá: Universidad de Alcalá. La Mancha: Universidad de Castilla. Tomado de: www.liceus.com ISBAN- 84-9714-028-1. De este autor se aprovechará el panorama que realiza sobre la crítica de la novela posmoderna, en el que aporta valiosa información sobre bibliografía de teóricos que han profundizado en la problemática.

2 La discusión en torno a este concepto se abordó en este trabajo desde los siguientes autores: Gianni Vattimo. "Posmodernidad, ¿una sociedad trasparente?". Giraldo, Fabio. (1991). Colombia: el despertar de la modernidad. Jorge Orlando Melo. "Algunas consideraciones globales sobre la modernidad". Salomón Kalmanovitz. "Modernidad y competencia". En: Viviescas, Fernando; Bogotá: Foro Nacional por Colombia. También, Zygmunt Bauman. (2003). Modernidad líquida. México: Fondo de Cultura Económica. En este trabajo se hace la distinción entre modernidad y modernización; entendida la primera como el proceso que permite, desde la reflexión y la crítica sobre el yo y el contexto, la construcción de una subjetividad; y la segunda, como la experiencia de una práctica sobre el mundo despojada de sentido y sensibilidad. La razón moderna (modernizada-instrumentalizada) que aquí se cuestiona, da cuenta de la segunda categoría. dogma religioso; manteniendo; inevitablemente, a Colombia (en ese entonces Nueva Granada), en un aislamiento y un atraso considerables durante casi dos siglos. Solo hasta muy entrado el siglo XVIII se desarrollan los primeros intentos modernizadores, los cuales comienzan por una búsqueda de la independencia y de la identidad.

Las élites criollas propician el desarrollo económico capitalista, la autonomía administrativa, la eliminación de la discriminación entre criollos y españoles y el ejercicio de una práctica científica que permite la creación de instituciones superiores. No obstante, al ser un proceso liderado por los grupos privilegiados de la sociedad, los cambios estructurales son muy pocos. Se presentan dos posiciones: un proyecto liberal, apoyado por un grupo de progresistas y el campesinado; $y$ uno conservador, cuya fuerza provenía de la Iglesia y los grandes latifundistas.

Los conflictos entre estas dos perspectivas ideológicas dificultan el advenimiento del laicicismo en las prácticas económico-sociales y reafirman una estructura mental que ha estado en el origen de la conformación del país y que aún se mantiene: la mentalidad católico-feudal ${ }^{3}$. Esta forma de ver el mundo cuyo origen es español, se impone en el país sobre otras formas paganas procedentes de los grupos indígenas y negros. Se convierte, con el paso de los siglos, en obligación doctrinal, materializándose, en las leyes y en el régimen educativo y, por tanto, en un orden de la representación.

Solo hasta el siglo XX, en la década de los noventa, la reforma a la Carta Constitucional propicia la entrada al campo social 4 de discursos y cuestionamientos que antes no se percibían, pues se margi-

3 José Luis Romero define este concepto como una mentalidad rural y estática donde "el mundo se concibe como predestinado por la voluntad divina y la libertad humana juega un papel mínimo. Es un orden marcado por la desigualdad y mediado por la infalibilidad de la autoridad terrena, sancionada por la divina, que obviamente no tiene límite" (Citado por Kalmanovitz; Viviescas; Giraldo, 1991: 311). Kalmanovitz toma esta conceptualización para explicar la resistencia que esta mentalidad ha ejercido en los procesos de construcción de pensamiento moderno en el país. (Citado por Kalmanovitz; Viviescas; Giraldo, 1991: 311).

4 La teoría de los campos de Pierre Bourdieu es el enfoque metodológico con el cual se aborda la problemática de lo literario en este estudio. Bourdieu, P. (1995). Las reglas del arte. Génesis y estructura del campo literario. Barcelona: Anagrama. 
nalizaban o no llegaban a consolidarse debido a la ausencia de espacios para la expresión. En ese momento la apertura a nuevas formas de la economía $\mathrm{y}$ a nuevas formas de simbolizar la realidad permite que se constituyan actos expresivos divergentes que hasta el momento no se visibilizaban ${ }^{5}$.

En este punto, la multiplicidad de manifestaciones discursivas genera una dinámica del disenso en lo religioso, cultural y artístico, cuya característica principal es el escape de la dialéctica del sentido6; es desde la proliferación infinita de referentes y de formas enunciativas que se articula una nueva manera de contar la experiencia.

El desvanecimiento de ese horizonte heredado de la tradición católico-feudal conlleva una revisión de los parámetros a partir de los cuales se articula un orden de la representación en lo literario en este siglo; para el caso de este estudio, desde el análisis de una novela colombiana de la primera década del siglo XXI: La celda sumergida, de Julio Paredes.

Es desde lo anterior que se plantea la siguiente hipótesis de sentido, la cual guiará la construcción de la reflexión en torno a la temática planteada.

La celda sumergida, de Julio Paredes, es una propuesta estética de comienzos del siglo XXI, que responde a la necesidad del campo literario de

5 El grupo de Investigación ISLC (Investigación Social y Sociocrítica de las Literaturas y las Culturas) de la Universidad Distrital Francisco José de Caldas, del cual la autora de este artículo es coinvestigadora, realizó un proyecto de investigación en torno a las nuevas posiciones estéticas que surgieron de la apertura del campo de la novela propiciado, en parte, por el reconocimiento de la diversidad que se hace en la Constitución del 1991. Este texto retoma parte de las reflexiones que en dicho ejercicio de indagación lograron concretarse. Como se precisó antes, los resultados pueden consularse en el centro de documentación del CIDC y muy pronto en el Sistema de Información de Literatura Colombiana de la Universidad de Antioquia, base 9, sub-base novela y la base 8, sub-base autores, SILC. www.udea.gov.co.

6 “... la emancipación consiste más bien en el desarraigo (dépaysement), que también es al mismo tiempo liberación de las diferencias, de los elementos locales, de lo que podríamos Ilamar en síntesis el dialecto. Una vez desaparecida la idea de una racionalidad central de la historia, el mundo de la comunicación generalizada estalla como multiplicidad de racionalidades locales -minorías étnicas, sexuales, religiosas, culturales o estéticas- que toman la palabra y dejan de ser finalmente acalladas y reprimidas por la idea de que solo existe una forma de humanidad verdadera digna de realizarse, con menoscabo de todas las peculiaridades, de todas las individualidades limitadas, efímeras, contingentes..." (Vattimo; Viviescas, Giraldo, 1991: 195). elaborar un orden de la representación que tenga en cuenta la multiplicidad discursiva en vivencias de los seres humanos actuales. De esta estructura emerge un cuestionamiento a la cosificación de los procesos de subjetivación por cuenta de la influencia de una razón instrumentalizadora de la experiencia humana.

El trabajo que desde dicho planteamiento se propone, procede de la siguiente manera: 1) Se caracteriza el género novelesco desde los principios de la conceptualización moderna, planteando una reflexión en torno a su transformación desde la particularidad de la estética posmoderna. 2) Se analiza la apuesta literaria en La celda sumergida como un ejercicio que permite la aproximación a los criterios estéticos que condicionan la producción en campo de la novela colombiana en el periodo seleccionado. 3) Se esquematiza la dinámica del campo de la novela colombiana, desde la problematización de una estética moderna central (la toma de posición de García Márquez') y su corolario posmoderno (como toma de posición disidente) Paredes, a partir de lo cual se verifica una lucha por la legitimación de un orden de la representación divergente en la actualidad.

\section{De la solidez moderna a la licuefacción posmoderna: la novela como género de las sociedades que producen para el mercado}

La novela es el "género del desamparo"; este es el planteamiento central de Georg Lukács en su obra de 1915, Teoría de la novela (Lukács, 1920, 1985). La forma novelesca es expresión de la orfandad de valores, es decir, es la materialización estética de un sistema que degrada a los seres humanos. Según esta conceptualización, el hombre emprende, a raíz de su crisis interior, una búsqueda de valores legítimos sin renunciar a la ilegitimidad del mundo. La

7 Gabriel García Márquez, a causa del prestigio y el alto grado de legitimación que ostenta, es la figura central cuya apuesta estética (en general moderna) ha establecido una forma de la práctica artística en el subcampo de la novela; por tanto, es el referente a partir del cual se evalúan los intentos de subversión y de lucha por el reconocimiento en la dinámica del campo literario colombiano. Esta percepción se argumentará en el cierre de este apartado. 
novela es una estructura percibible desde el accionar de su héroe, el cual encarna la problemicidad de la modernización.

Lucien Goldmann, en Para una sociología de la novela (Goldmann, 1964, 1967), decide abordar el género novelesco desde la mediación por el valor de cambio planteando que en la novela existe una transposición de la vida de una sociedad individualista. Así,la ruptura entre el yo que busca valores "auténticos" y el mundo se agrava a causa de la degradación que el sistema económico genera. En este sentido, la novela cumpliría la función de denuncia de la reducción de lo humano a la razón instrumental, al simple intercambio por la ganancia. La de la novela es, entonces, homóloga a la estructura del sistema económico del cual es producto.

Bajtin, por su parte, en Problemas literarios y estéticos (Bajtin,1975, 1986), plantea que la novela es un género que nace del cruce enunciativo, ya que gracias a su naturaleza híbrida absorbe los demás géneros, los "noveliza" volviéndolos, por tanto, plásticos y dialógicos. La novela, desde Bajtin, tiene en su configuración la risa, la parodia y los elementos autocríticos, lo que la convierte en el género más adecuado, a diferencia de la epopeya y la tragedia, para dar cuenta de la realidad del hombre de la modernidad.

Según Bajtin, los géneros mayores tratan de un momento histórico que le es lejano al hombre y reproducen el discurso de una élite que perdió pertinencia en el decurso de la historia, son monológicos; mientras la novela, gracias al distanciamiento y a la evaluación del mundo que hace el autor creador de su realidad, es dialógica, y por tanto, crítica.

Las anteriores conceptualizaciones parten de una percepción moderna del género: “... La novela modernista se caracterizaba por la búsqueda de una coherencia por lo que la obra era concebida respondiendo a una estructura que permitiera el ensamblaje de sus diferentes partes o facetas" (Gurpegui, 2005). La novela, percibida desde la posmodernidad, rompe con ese llamado al orden y aboga por una representación que en lugar de ser una "homología" con la estructura social, opta por la multiplicidad de referentes en los que se controvierte la distinción entre realidad y ficción.

La novela de la modernidad tardía o posmoderna busca plasmar el prosaísmo, la liquidez $z^{8}$ la fugacidad de la experiencia real; por esa razón en ella el concepto de estructura está diluido, se sustituye por "principios como [...] la contingencia, la discontinuidad y la fragmentación". Esto significa la recusación de un orden de la representación legitimado y el llamado a la no dependencia de la razón logocéntrica. Este hecho da origen a nuevas formas del género, formas que cambian la relación que tradicionalmente entablaban el autor y el lector, ya que nuevos pactos narrativos se emprenden. Lo ficticio ya no da cuenta de una realidad que previamente ha sido prescrita, ya no se trata de ficcionalizar el mundo del ser humano a partir de una estructura narrativa coherente y ordenada, se trata de mostrar la ficción que existe como tal en la experiencia de la realidad. Por tanto, el lector debe asumir una posición de co-creador, pues el mundo que presencia en la obra es el mismo en la realidad; es decir, un entorno discontinuo, caótico e impreciso. Desde esta perspectiva, la vivencia es en sí misma ficción y para ella no hay un orden preestablecido, por lo cual para enfrentársele es necesario tener competencia, capacidad de desciframiento discursivo.

La ruptura con el pacto narrativo moderno se hace patente en la estructura de la novela; más bien, en su desestructura, hecho que es el resultado de la multiplicación de voces y medios para la expresión, de la rapidez con que fluye la información y del proceso de igualación de las prácticas que está desatándose en todas las sociedades por cuenta de la globalización y las políticas económicas neoliberales. La mediación del mercado no ha desaparecido en la novela, solo se han trasformado los recursos para su explicitación, hecho que se aborda actualmente desde diversas conceptualizaciones que iluminan una aproximación a la definición del género en la actualidad:

8 "Liquefacción" es el término de Bauman para caracterizar el orden de la representación posmoderna (Bauman, 2003). 


\section{La fabulación como una forma de representación de la experiencia humana a partir del juego creativo}

Se recurre a múltiples formas en las que se destaca, ante todo, el distanciamiento del mundo de la experiencia. Es frecuente ver en este tipo de ficciones que el autor experimente con formas como el romanticismo, la alegoría o el mito. Es evidente en esta ficcionalización una resuelta apuesta por la irracionalidad 9 .

\section{La reflexión que cuestiona la pasividad}

Aquí el lector, acostumbrado a aceptar categorías preestablecidas, es cuestionado por caer en falacias miméticas. Esta preocupación lleva a que la novela se cuestione a sí misma, en especial por sus procedimientos para la ficción, lo cual desvela sus relaciones internas. Ahora la realidad no es el referente principal, sino la indagación de los mecanismos de la ficción ${ }^{10}$.

La exposición de la propia ficción es una precisión dentro de la cual puede ubicarse una definición de la novela posmoderna; este fenómeno tiene diversos nombres semánticamente similares al de novela reflexiva: la novela como género de la autoconciencia (the novel as a self-conscious genre) ${ }^{11}$; la novela autogeneradora (the selfl-begetting novel) ${ }^{12}$; metaficción ${ }^{13}$, etc. Todos ellos aluden al mismo fenómeno, que es la complejidad en el tratamiento de la realidad. El ha-

9 "It is my contention that modern fabulation grows out of an attitude which maybe called 'fabilism', just as nineteenth-century realism grew out of an earlier attitude called positivism. Fabulation, then, means not a turning away from reality, but attempt to find more subtle correspondences between the reality which is fiction and the fiction which is reality". (Robert Scholes. (1979). Fabulation and Metafiction, Urbana: University of Illinois Press. Citado por Gurpegui; Ramón, 2005)

10 "... the reflexive novel seeks to examine the acting of writing itself, to turn away from the project of representing an imaginary world to examine its own mechanism". (Michael Boyd. (1975). The Reflexive Novel Fiction as Critique, London and Toronto: Associated University Press. (Citado por Gurpegui, 2005).

11 (Robert Alter. (1975). Partial Magic: The Novel as a Self-Conscious Genre. Berkeley and Los Angeles: University of California Press. (Citado por Gurpegui; Ramón, 2005).

12 Steven Kellman. (1980). The Self-Begetting Novel. New York: Columbia University Press. Citado por Gurpegui, 2005.

13 Patricia Waugh. (1984). Metafiction, London and New York: Methuen. (Citado por Gurpegui; Ramón, 2005). cer explícito el artificio es un claro rechazo al pacto narrativo del logocentrismo, lo que implica asumir una subjetivación del mundo. El género novelesco, entonces, se vuelca sobre sí mismo e indaga sobre el tipo de ficcionalidad que construye.

Orfandad, crítica, ambigüedad, fábula o autorreflexión son elementos que ayudarán a comprender el orden de la representación que en la novela de Julio Paredes, La celda sumergida, se elabora para entrar al campo literario a luchar por un orden de la representación divergente.

\section{La fabulación y la metaficción en La celda sumergida: una evidencia de la subversión simbólica del campo literario en la actualidad}

Los sentidos que para el pensamiento racional ilustrado son usados como medio de distanciamiento de la realidad permiten conocer el mundo sin que haya lugar a su falseamiento. En el pacto narrativo ${ }^{14}$ de esta novela, la realidad que se cuenta es la que se articula en la mente del protagonista, desde ahí los sentidos pierden su función de receptores y se transforman en herramientas de la imaginación, de donde emerge el desciframiento de una nueva verdad, una que no está al alcance de los intereses de la modernización.

Las líneas con que abre el texto presentan el ejercicio fabulatorio del personaje protagonista:

Me pareció lamentable, casi triste, acercarme a la promesa de un fabuloso yacimiento de monstruos cuando no me quedaba más de un día antes de abandonar, y para siempre, Nueva York. En un primer reflejo, con la certeza inmediata de bordear un descubrimiento inaudito, no supe explicar por qué este conglomerado de máscaras que empecé a seguir desde un par de horas atrás, caminando por calles que, además, no pisaba por primera vez, escapó a mis anteriores exámenes callejeros, a las exploraciones que solía hacer con los binóculos (p. 15).

14 Pacto narrativo: es “... la doble relación, implícita o explícita, que toda obra narrativa establece, por un lado, entre el autor y el virtual lector, y por otro, entre un narrador y un narratario, sea este designado o solo sobreentendido". (Bourneuf ; Ouellet, 1989). 
En esta apertura de la novela se plantea una ruptura con la técnica realista ${ }^{15}$; es decir, con el tipo de narración propio del pensamiento individualista ilustrado en el que la objetivación prima y la credibilidad es una búsqueda fundamental; se rompe con el orden de la representación canonizado por la mirada occidental a partir del descubrimiento de una realidad más significativa que no es percibible a través de los sentidos físicos. Esta posición es consecuente con la opción axiológica que se ha intuido en la obra, en ella se elige subjetivar la realidad desde la mirada del personaje principal; para esto, el monólogo resulta ser la forma de comunicación más propicia ${ }^{16}$. Es la interioridad de un ser humano, la imaginación de un yo que se manifiesta en estos primeros renglones. Se escucha la voz de un personaje que, en primera persona, se habla a sí mismo y quien, por lo minucioso de sus descripciones, evoca implícitamente a un interlocutor.

A medida que avanzaba y descubría más siluetas camufladas entre otros ornamentos, pensé que asistía al posible y cercano despliegue de un número incontable de figuras con el porte de una belleza violenta, expuestas en combinaciones que me hicieron imaginar, en la secuencia que formaban, el rompecabezas de un sueño. Por andar siempre en una distracción desaforada y durante los últimos días también nerviosa, esta magnífica sociedad en piedra que vislumbraba ahora habrá desfilado ante mis ojos sin ningún enfoque, como los adornos menores de un paisaje de utilería. Así, cuando me

15 “...Realismo significa reconocimiento de que el hecho de la creación no se fundamenta sobre una abstracta 'medianía' como cree el naturalismo, ni sobre un principio individual que se disuelve en sí mismo y se desvanece en la nada, sobre una expresión exasperada de aquello que es único e irrepetible [...] El verdadero gran realismo retrata al hombre total y a la sociedad total, en cambio de limitarse en algunos de sus aspectos. Georg Lukács. (1965) Ensayos sobre el realismo. Buenos Aires: Siglo Veinte.

16 Según Genette, toda narración está por definición en tercera persona; sin embargo, hay una relación alterada entre el narrador y su protagonista cuando este protagonista es su propio yo en el pasado; dicha alteración se hace más fuerte cuando ese yo se presenta sin mediación, es decir, es autogenerado. Esto amplía las posibilidades de las funciones irónicas o líricas, reductivas o expansivas, subverbales o supraverbales que una psiconarración puede realizar, a esto se le denomina monólogo autónomo, el cual se refiere a la expresión de la vida de un personaje en primera persona, sin el gobierno de una mediación narrativa. (Cohn.; Sulla,1996: 205). tropecé con el último de los demonios, la gárgola que me pudo enlazar con ese otro mundo invisible, sospeché que actuaba como otra sombra en la mitad de ninguna parte, deambulando durante años por el orden ilusorio de una ciudad a la que en realidad nunca había llegado (p. 15).

Si bien es manifiesta la representación de un ego, el otro es convocado. Los enunciados de ese yo con que abre la novela actualizan un acto de comunicación en el que se participa como espectador, como "fisgón"17 de una interioridad.

Así, sospeché que actuaba como otra sombra en la mitad de ninguna parte, deambulando durante años por el orden ilusorio de una ciudad a la que en realidad nunca había llegado (p. 15).

Esa disposición del discurso, de modo que el otro también participe, hace que la enunciación sea abierta, fluida y audible, es decir, externa. La subordinación de las oraciones es el recurso del autor para invitar al otro a participar. A través de las comas separa algunos periodos lingüísticos en los que amplía una descripción, explica una situación o deja entrever un estado anímico ("Me pareció lamentable, casi trise...”); de esta manera entra en contacto con el otro.

Más que sorprendente, resultaba inverosímil que después de tantas acometidas con el ímpetu y la urgencia de precipitarme al interior de las calles, moviéndome rápido y con familiaridad por cualquier distrito de Lower Manhatan a Coney Island o del Soho a Queens, no me hubiera percatado antes del soberbio espectáculo de su presencia (p.14).

El personaje protagonista de esta novela, José Alejandro, es un arquitecto cuyos inicios como profesional parecían prometedores; un individuo adaptado al sistema y enamorado de su mujer. Una vez emigra con ella a Nueva York, para avanzar en su formación académica, entra en una especie de shock

17 "[...] cuando el hombre y la vida privados entraron en la literatura [...] Surgió la contradic ción del carácter público de la propia forma literaria y la privacidad de su contenido [...] La literatura de la vida privada es, en esencia, la literatura del fisgoneo, del ver y oír a hurtadillas 'cómo viven los demás'" (Bajtin, 1975, 1986: 315). 
que paraliza su movilidad como ser social funcional y genera en él una suerte de autismo, una forma de incomunicación que se manifiesta a través de una obsesión voyerista por construcciones arquitectónicas y por recorridos interminables en las calles de la ciudad; estos se constituyen en el único medio para significar la realidad.

Dicha obsesión va de la mano de una exacerbación de la imaginación: cada situación, cada experiencia, cada espacio real o imaginario, cada nuevo encuentro motivan sensaciones que llevan implícitas el deseo de distanciarse del mundo y de alcanzar la plenitud espiritual. Su anhelo principal se resume en la creación de la edificación perfecta; diseñar el espacio arquitectónico ideal es su imperativo categórico.

La fabulación, que se manifiesta como ensoñación o como alteración de los sentidos, es un artilugio defensivo que permite que el protagonista busque una salida a la razón instrumental desde la irracionalidad. Aquí la pérdida de la lucidez se presenta como un peligro para el ser humano que se mueve en un mundo de reglas lógicas; sin embargo, a través de la irracionalidad el personaje protagonista halla una nueva cordura que dota de sentido al mundo que habita y que le permite reencontrarse con su yo.

La exaltación a causa del fabilism ${ }^{18}$, del juego con los sentidos, invita a una complicidad voyerista. La otredad se asimila con el yo ${ }^{19}$, por eso el horizonte

18 Es un recurso ficcional experimental "que está dirigido hacia un mundo imaginado, distanciado del mundo de la experiencia" (Gurpegui; Ramón, 2005).

19 M. Auge y Paul Ricoeur elaboran una conceptualización sobre la otredad que se aproxima a lo que aquí se elabora. Según Marc Augé puede concebirse al otro como una abstracción, una instancia de la configuración psíquica de todo individuo; el otro es el distinto del yo, es el sujeto- objeto susceptible de ser conocido. Paul Ricoeur define la otredad mediante un juego de palabras: el otro es el sí mismo como otro, es decir, el otro distinto del yo, es como otro yo.

Estos autores franceses argumentan lo anterior, sosteniendo que lo otro no es solo la contrapartida de lo mismo, sino que este pertenece a su constitución íntima. Lo otro distinto del sí (del yo) afecta la comprensión del sí, es decir, la aceptación de la otredad implica la negación de la mismidad; en el momento en que un individuo opone su mismidad a la mismidad de otro individuo, implícitamente está ocupando su lugar. Para ambos autores, la existencia del yo supone de antemano la existencia del otro. El otro no es uno de los objetos del pensamiento, sino como el yo, es un sujeto de pensamiento. a partir del cual se organiza la representación es de doble naturaleza: objetivo y subjetivo. Esta manera de expresar una forma de ver el mundo a la vez particular y social se manifiesta lingüísticamente desde el uso de un pretérito indefinido que desde el yo pone en primer plano el espacio. Aquí la imaginación del personaje narrador (lo particular) se vincula a una realidad objetiva que es la ciudad (lo social). Los "monstruos", las "gárgolas" que el autor fabula con su mirada (imaginación) son parte de la arquitectura urbana de Nueva York (realidad objetiva). El yo narrador y el espectador implícito se unen para configurar un modo comunicativo complejo, en el cual la relación interioridad-exterioridad elude una única codificación.

Al principio es difícil identificar los referentes que alude: “... un fabuloso yacimiento de monstruos...", “... un descubrimiento inaudito..., “.... conglomerado de máscaras...", “... siluetas camufladas entre otros ornamentos..., “.... figuras con el porte de una belleza violenta...", "... el rompecabezas de un sueño..., “... el último de los demonios.... A primera vista estas enunciaciones discursivas ${ }^{20}$ anuncian el necesario ejercicio de desciframiento de un código que parece inaccesible. Desde este primer párrafo se evidencia de manera contundente una perspectiva alterada por la imaginación, una mente cuya expresión es muy particular, una mirada perturbada y que es perturbadora.

Con la aparición de los bichos, sentía que abría de nuevo los ojos y veía, esculpidos de pronto en las paredes de estos edificios, los animales frenéticos

Tanto el yo como el otro son semejantes, ya que miran el mundo como una naturaleza común; juntos edifican colectivos de personas capaces de conducirse a su vez en la escena de la historia, son personalidades de un grado superior. El otrototaliza al yoy le ayuda a fortalecer su identidad. Véase Marc Augé. (1995). El sentido de los otros: actualidad de la antropología. Barcelona: Paidós. Paul Ricoeur. (1996). Sí mismo como otro. México: Siglo XXI.

20 Concepto de Emile Benveniste que se refiere al uso no impersonal de la lengua, este medio de comunicar ideas es subjetivo y está cargado de connotaciones, emplea libremente todas las formas personales del verbo, su propósito es cargar de sentidos los enunciados. La enunciación histórica, por el contrario, presenta los hechos sin la intervención de un yo particular, es impersonal, aparece en formas de la tercera persona y su propósito es que los hechos se cuenten por sí mismos. (Benveniste, 1966: 237-250). 
que, inconsciente, tenía agazapados en alguno de los hemisferios del cerebro (p. 15).

La voz narradora en este primer encuentro con el texto arroja mucha información en torno al tipo de subjetividad que se representa en la obra. Esta comunica la presencia de una individualidad que se mueve en un entorno no racionalizado desde el logocentrismo; de hecho, la relación realidad-ficción es cuestionada. El narrador, al presenciar una suerte de epifanía en su encuentro con las "gárgolas", se cuestiona sobre la lucidez de su mente. Esta actitud del personaje es consecuente con el lugar en el que se ubica Julio Paredes dentro de la lucha simbólica. Si bien la modernidad garciamarquiana aborda la realidad desde la fantasía, en la propuesta posmoderna de La celda sumergida, la fantasía ya no tiene un referente en la realidad objetiva del mundo, a causa de que esta se origina en la mente de un individuo particular. En este sentido, el origen de la fabulación no es la realidad jerarquizada por el pensamiento moderno, es una realidad que emerge de una clara intención de ficcionalizar el mundo.

La novela cierra con un sueño del personaje, en el cual este se pasea en el interior de su fantasía estética; en ella se encuentra con un hombre que, por las descripciones que da, podría ser su padre. Sin embargo, sorprende al lector cuando descubre que ese personaje enigmático no es otro que el escritor. Este, encima de su escritorio tiene el arrume de hojas que narra la historia que se acaba de leer. Este cierre es bastante significativo, ya que una vez más pone a prueba la eficacia del pensamiento racional, elaborando un mensaje en el que lo inexplicable se vuelve más relevante que aquello que la lógica demuestra.

Volví a ver el dibujo y adiviné que en los folios cubiertos por la imagen del castillo estaba el libreto que, en su avance, me había traído hasta este cuarto. ¿Estaba por fin al lado de la fuerza no terrenal que sostenía mi vida? ¿De la mente que por sus circunvoluciones y lóbulos había codificado mis accidentes sentimentales, la dicha con Cecilia, los olores del invernadero y las sombras en los espejos? Supe que no me iba a hablar, que no podía decirme nada, pero reconocí en sus ojos la voluntad que me puso a sondear lo desconocido y sus jardines, a diseñar casas efímeras y sin salida, a creer en los fantasiosos recuerdos de mi pasado o en las visiones de la miseria... (p. 195).

La metaficción, es decir, el constante cuestionamiento que el personaje hace al escritor sobre su proceso de creación, es un intento por parte de Paredes de hacer más complejos los procesos comunicativos dentro de la obra; plantea un manejo de la realidad que rompe con la forma discursiva privilegiada por la mirada tradicional. Esta ruptura tiene implícito un cuestionamiento que es de dos órdenes; por un lado, se encuentra una crítica a los sistemas que privilegian el mundo objetivo, la realidad percibida a través de los sentidos; el hecho de poner a hablar a un personaje con su escritor conduce todo el movimiento de la problemática hacia una instancia donde se reivindican esas formas de percibir la realidad que no son positivistas. De otro lado, se pone en cuestión el poder del escritor como elemento activo en la ficción de la obra, ya que al interactuar con el protagonista rompe con un esquema propio de la tradición en el que está prohibido subvertir los roles. Esta fractura no es solo formal, sino también ideológica. A través de esta forma de enunciar la realidad se denuncia la ausencia de espacios para que la subjetividad se manifieste ${ }^{21}$.

Desde esta perspectiva, la propuesta de Paredes se inscribe en la tendencia escrituraria de las actuales configuraciones estéticas en el campo de la novela, en la cual "las ficciones contemporáneas se vuelven más conscientes de ser construcciones imaginarias, fabricadas arbitrariamente y situadas fuera del alcance de la realidad, puesto que el mundo real es únicamente una ilusión, es solo un artificio inventado a través del lenguaje"22.

21 "Metafiction thus converts what it sees as the negatives values of outworn literary conventions into the basis of a potentially constructive social criticism. It suggest, in fact that there may be as much to be learnt from setting the mirror of art up to its own linguistic or representational structures as from directly setting up to hypothetical human nature that somehow exists as an essence outside historical systems of articulation". (Waug; Gurpegui; Ramón, 2005)

22 (Gurpegui; Ramón, 2005). 


\section{La divergencia en la configuración de un nuevo orden de la representación en la novela colombiana de la primera década del siglo $X X I$}

Cuando García Márquez llega al campo literario a disputar una posición (a mediados de la décaa de 1950) el tema de si existía una literatura nacional estaba en el centro de la discusión crítica. La autonomía apenas estaba configurándose, razón por la que la producción novelística era considerada "adolescente, sin autonomía de conciencia ni libertad de criterio"23. Este hecho generó en algunos autores (específicamente del Grupo de Barranquilla) el interés por participar de una nueva forma de la producción simbólica del país. La herencia del naturalismo, el costumbrismo y la novela terrígena abrió un espacio de los posibles hacia propuestas más arriesgadas e innovadoras en cuanto a la manera de dar forma a las enunciaciones ${ }^{24}$. Esta intención de cambio coincide con una tendencia general de reacción frente a la modernización social en América Latina; entonces la participación de García Márquez deviene relevante porque su apuesta se vincula con una resemantización del orden de la representación heredado de Europa.

Se entrevé en la propuesta garciamarquiana un diálogo crítico y estructurado con la modernidad de Colombia, y una búsqueda de un buen fin, uno del Caribe, para su proyecto de libertad individual. Modernidad caribeña porque, ante todo, configura una intención emancipadora de discursos literarios precedentes, de órdenes de la representación preestablecidos y que, en ese momento, no comunicaban la necesidad de pertenencia a una identidad cultural específica, en este caso, la latinoamericana. Por ello, las obras de carácter mítico y fundacional que hicieron parte de esta nueva perspectiva discursiva

23 Cita de Rafael Maya tomada de Pineda-Botero, Álvaro. (1990). Del mito a la modernidad. Bogotá: Tercer Mundo Editores.

24 “Para que las osadías de la búsqueda innovadora o revolucionaria tengan posibilidades de ser concebidas, tienen que existir en estado potencial en el seno de sistemas de posibilidades ya realizadas, en forma de lagunas estructurales que parecen estar esperando y pidiendo ser colmadas, en forma de direcciones potenciales de desarrollo, en forma de vías posibles de búsqueda". (Bourdieu, 1995). indagaban en torno a la pregunta sobre qué es lo latinoamericano, aglutinando así una definición de lo propio y de las formas consideradas como más auténticas para abordar la realidad.

No obstante, esa emancipación no es total, solo se trataba de "remplazar el conjunto heredado de los sólidos defectuosos y deficientes por otro, mejor o incluso perfecto, y por eso mismo inalterable" (Bauman, 2003: 9). Es decir, se abogó por desautorizar, desacralizar y negar el pasado, específicamente el que reivindicaba el canon estético europeo, para poner en su lugar una razón que desmonte "la armadura protectora forjada por las convicciones y lealtades que permitía a los sólidos resistirse a la "liquefacción" (Bauman, 2003). El nuevo horizonte de la representación que se impone ya no es europeo, pero sigue fijado a principios y lógicas enunciativas centrales.

El orden garciamarquiano da cuenta de unos valores a partir de los cuales se configura una subjetividad, que aunque cuestionadora del marco impuesto por la mirada europea, continúa sólida, definida por preconcepciones sobre el deber ser del hombre y el mundo ${ }^{25}$. Esta puesta en forma propone un orden de la representación que es en realidad un "verdadero" orden, es decir, un sistema enunciativo orientado a las particularidades de una cultura, que habla desde unos criterios considerados propios y que articulan una vivencia que solo atañe a los latinoamericanos.

Es desde esta perspectiva que se inician las insubordinaciones dentro del campo, pues ese orden del Caribe, ese latinoamericanismo, excluye y simplifica la multiplicidad discursiva del país. García Márquez se torna una figura preasignada, desde la que se compara y se resignifica la producción simbólica en el campo. Este hecho conmina, es el envite, para que formas enunciativas nuevas se instalen y propongan configuraciones estéticas no determinadas de antemano, ni precedidas por criterios evaluativos

25 Al respecto puede consultarte el artículo "El general en su laberinto: una apuesta por la ilustración latinoamericana". (Folios, 20, 45-54, 2004. Universidad Pedagógica Nacional). En este texto se analiza la postura del autor en la que cuestiona la cosificación de la imagen del Libertador por parte del discurso oficial y aporta una representación del prócer en la que se apuesta por héroe moderno del Caribe. 
preasignados. Llega el poder de la "licuefacción" que como tal desintegra el sistema enunciativo precedente ubicándose ahora en el individuo en lugar de buscar la definición de una identidad cultural. Lo posmoderno, entonces, se convierte en esa suerte de cambio de conciencia difícil de precisar. Al difuminarse la idea de estructura organizadora y autoevidente, llega el rechazo a la razón totalizante, y a la idea de unidad entre países, pero al mismo tiempo es necesario aprender y tolerar la diversidad de dialectos que se abren paso ante licuefacción de los marcos representacionales.

En el campo de la novela colombiana de los últimos años puede verse la influencia de la Constitución de 1991.La articulación de posiciones nuevas da cuenta de una diversificación y ampliación de la dinámica creación-producción-difusión de lo literario. Esta apertura ha posibilitado la aparición de una clase de autores socialmente distinta que se caracteriza por la irreverencia y la indiferencia hacia normas impuestas por la posición predecesora y con gran poder simbólico de García Márquez.

Este nuevo linaje manifiesta su necesidad de distinción desde la recusación de la práctica estética central, la cual reglamentó el juego por el poder de legitimación. Como se vio en el análisis de La celda sumergida, en la propuesta de Julio Paredes hay una reflexión en torno a los mecanismos de la ficción, reflexión que surge de un planteamiento sobre la idoneidad para poner por escrito una determinada percepción de la realidad que experimenta el ser humano contemporáneo, cuando esta, actualmente, aparece compleja e irreductible a un único sistema de la representación. En ese sentido, su apuesta es disidente con respecto al horizonte que durante décadas ha registrado las vivencias de los individuos, pues de antemano problematiza la escritura, es decir, cuestiona la clarividencia de los consagrados que, desde una actividad que se ha restringido a unos cuantos principios evaluativos, hablan de una sociedad que se caracteriza por la constante modificación de sus valores. Por ello su toma de posición, la cual se inscribe en una lectura muy particular de la realidad y desemboca en "una versión privada de la modernidad, en la que el peso de construcción de pautas y la responsabilidad del fracaso caen primordialmente sobre los hombros del individuo". En otras palabras, esos planteamientos que movilizaron desde García Márquez una búsqueda de la identidad literaria, en este momento han envejecido y la percepción de lo individual prima sobre la del colectivo. Esto es visible en la configuración del personaje protagonista: José Alejandro no se identifica con ninguna raíz; la errancia y la no pertenencia son sus únicos distintivos. El personaje de la novela es posmoderno en el sentido de que está más allá de los marcos que tradicionalmente representaron al ser humano. Es una nueva definición del sujeto, en este caso más independiente, más autónomo y menos socializado. Esta propuesta enunciativa es coherente con el tipo de posición en el que se instala Paredes para la lucha simbólica, ya que sus intereses artísticos se enfocan en temáticas contemporáneas que tocan las experiencias de seres humanos que habitan ciudades y sociedades en las que las prácticas productivas se han desregularizado. Eso es La celda sumergida, un orden del discurso que se opone a la vacuidad y al sinsentido del mundo objetivo. El mundo interior es rico y desde este se logra intensificar la experiencia. Su propuesta provoca "la huida, el escurrimiento, la elisión, la capacidad de evitar, el rechazo concreto de cualquier confinamiento territorial, y de sus engorrosos corolarios de construcción y mantenimiento de un orden, de la responsabilidad por sus consecuencias y de la necesidad de afrontar sus costos" (Bauman, 2003: 17). Л 


\section{Bibliografía}

Angulo Noguera, Y. (2004, El general en su laberinto: una apuesta por la ilustración latinoamericana. Folios, 20, 45-54. Bogotá: Universidad Pedagógica Nacional.

Augé, Marc. (1995). El sentido de los otros: actualidad de la antropología. Barcelona: Paidós.

Bajtin, Mijail. (1986). Problemas literarios y estéticos. La Habana: Editorial Arte y Literatura (Edición original en ruso, 1975).

Bauman, Zygmunt. (2003). Modernidad líquida. México: Fondo de Cultura Económica.

Benveniste, Emile. (1966). Problèmes de linguistique genérale. Paris: Editions Gallimard.

Bourdieu, Pierre. (1995). Las reglas del arte. Génesis y estructura del campo literario. Barcelona: Anagrama (Original en francés, 1992).

Bourneuf, Roland; Ouellet, Réal. (1989). La novela. Barcelona: Ariel.

Giraldo, Luz Mery. (2000). Narrativa colombiana: búsqueda de un nuevo canon, 1975-1995. Bogotá: Pontificia Universidad Javeriana.

Goldmann, Lucien. (1967). Para una sociología de la novela. Madrid: Ediciones Ciencia Nueva. (Edición original en francés, 1964).
Gurpegui Palacios, José Antonio; Torrijos, Ramón (2005). Contexto y perspectiva general del posmodernismo. Alcala: Universidad de Alcalá. La Mancha: Universidad de Castilla. www.liceus.com ISBN- 84-9714028-1

Lukács, Georg. (1985). Teoría de la novela. Ensayo histórico-filosófico acerca de las formas de la épica grande. México: Grijalbo (Original en alemán,1920).

Lukács, Georg. (1976). La novela histórica. Barcelona: Grijalbo (Original en alemán, 1911, 1915).

Paredes, Julio. (2002). La celda sumergida. Bogotá: Alfaguara.

Pineda-Botero, Álvaro. (1990). Del mito a la modernidad. Bogotá: Tercer Mundo Editores.

Sistema de Información de Literatura Colombiana de la Universidad de Antioquia, base 9, subbase novela y la base 8, subbase autores, SILC www.udea.gov.co.

Sulla, Enric. (1996). Teoría de la novela. Antología de textos del siglo XX. Barcelona: Grijalbo.

Ricoeur, Paul. (1996). Sí mismo como otro. México: Siglo XXI Editores.

Viviescas, Fernando; Giraldo, Fabio. (1991). Colombia, el despertar de la modernidad. Bogotá: Foro Nacional por Colombia. 